\title{
Pattern And Prevalence Of Rheumatic Heart Disease By Echocardiographic Evaluation
}

\author{
${ }^{*}$ R.K. Shah, A.B, Upadhyaya, L.P. Tibrewala, P.R. Regmi, K.P. Acharya, \\ H.H, Khanal
}

\section{Background}

The pattern of cardiac disease differs from one region of the world to that of another. Rheumatic heart disease is still widely prevalent in Nepal. The patterns and natural history is considerably different from what is seen in developed countries. Few studies had been done in Nepal to address pattern of heart diseases. Need of a large study to fill the gap and to show the profile of heart disease is there. This paper aims at providing the profile of heart disease as seen in Bir Hospital.

\section{Materials and Methods}

The patients who came for out patient evaluation and indoor admission between March 1986 to February 2001 were covered in the study. Total number of cases was 11,290. Data Analysis done among 10,436. Gases Patients having heart disease were 8654 while normal echocardiograms were 1782. Further data analysis done among disease cases only, $2890(33.4 \%)$ cases were of Rheumatic heart disease.

\section{Results}

Females outnumbered males (1.36:1) The number of patients having mitral stenosis alone was $976(33.7 \%)$, mitral stenosis and mitral regurgitation $634(21.9 \%)$, mitral regurgitation only was seen in 404 (14.0\%). Juvenile mitral stenosis was $197(6.8 \%)$ and Juvenile rheumatic heart disease was $527(18.2 \%)$. Patients having aortic regurgitation alone was $106(3.7 \%)$, aortic stenosis only was seen in $60(2.1 \%)$, aortic stenosis and aortic regurgitation $92(3.2 \%)$, patients who were having involvement of both mitral and aortic valves was $763(26.4 \%)$ Patient having single valve lesion was $1934(66.9 \%)$ with pure mitral valve in 1636 (56.6\%) and only aortic valve in 281 (9.7\%). 


\section{Conclusion}

Rheumatic Heart disease was most common heart diseases (33.4 percent). Females outnumbered males (1.36:1) Commonest valvular lesion was mitral stenosis (33.7 percent). Juvenile mitral stenosis was common (6.8 percent) and Juvenile RHD (18.2 percent) Single valve lesion was 2.5 times commoner (66.9 percent) than double valve (26.4 percent). 